\title{
HIGH RESOLUTION MAGNETIC FIELD SIGNATURES OVER AKURE AND ITS ENVIRONS, SOUTHWESTERN NIGERIA
}

\author{
Cyril C. Okpoli \\ Department of Earth Sciences, Faculty of Science, Adekunle Ajasin University, PMB 1, Akungba-Akoko, Ondo State, Nigeria \\ *Corresponding Author E-mail: cyril.okpoli@aaua.edu.ng
}

This is an open access article distributed under the Creative Commons Attribution License, which permits unrestricted use, distribution, and reproduction in any medium, provided the original work is properly cited.

\section{ARTICLE DETAILS}

\section{Article History:}

Received 8 August 2018 Accepted 9 September 2018 Available online 8 February 2019

\section{ABSTRACT}

Aeromagnetic data over Akure, Southwestern Nigeria was quantitatively and qualitatively analyzed to unravel subsurface magnetic anomalies. The analyses made on the IGRF corrected aeromagnetic data acquired was used to estimate depth to anomalous sources using 2-D power spectrum, werner deconvolution and 3-D Euler deconvolution. We gridded and sampled the aeromagnetic dataset; while the spectral analysis transforms the spatial data into frequency domain and provides a relationship between radially average spectrum of the magnetic anomalies and depths to the respective sources. Werner and Euler estimate and examines the shape, type of magnetic field within a window and calculate 3-D source locations based on its structural index. The characteristic nature of the magnetic anomalies as expressed by the profiles that is indicative of the different rock types (charnokite, porphyritic granite, grey gneiss, migmatite). Qualitative interpretation results revealed the following ranges for reduction to equator, upward and downward continuation, analytical signal, vertical derivative as; $-418.29 \mathrm{nT}$ to $532.35 \mathrm{nT}$, $-96.7 \mathrm{~T}$ to $175.4 \mathrm{nT},-544.53 \mathrm{nT}$ to $597.70 \mathrm{nT},-0.0 \mathrm{nT}$ to $2.199 \mathrm{nT},-0.1 \mathrm{nT}$ to $0.1 \mathrm{nT}$; while the quantitative interpretation results revealed-power spectrum, werner deconvolution and euler deconvolution as: $3.0 \mathrm{~m}$ to $11.0 \mathrm{~m}, 20.6 \mathrm{~m}$ to $650 \mathrm{~m}$, $166.29 \mathrm{~m}$ to $-323.05 \mathrm{~m}$ respectively. Location, source and depth of magnetic anomaly have been unraveled.

\section{KEYWORDS}

Akure, Deconvolution, Qualitative interpretation, anomalies, Nigeria.

\section{INTRODUCTION}

Airborne magnetic techniques have taken a major character in studies of regional Precambrian basement geology. The technique is principally complementary for structural and lithological differentiations revealed by lateral variations in the physical properties of the crystalline rocks. Lithospheric configurations are usually classified based on the trends and directions of magnetic anomalies. Structural episodes may be deduced by categorizing and investigating the alterations in magnetic signatures, grades of metamorphism, deformation history and of the regional basement geology, which may show their origin as well as structural history.

Government-funded aeromagnetic programme supply the geoscientific and industry community with recent data that are essential to the exploration for mineral resources and for general understanding of the geology region. In Nigeria, most of the previous airborne surveys have covered onshore regions. However, the survey in 2003 and 2009 by Fugro included significant offshore areas. Approximately one fourth of the 2009 airborne survey areas are offshore and includes remarkable areas for its hydrocarbon potential. Based on a study, high-resolution airborne magnetic data were recently collected in an Akure region and its surrounding towns to improve the regional geologic understanding of the subsurface geology $[1,2]$. Qualitative and quantitative analyses of the dataset were integrated to obtain a preliminary interpretation. The primary sources of aeromagnetic anomalies are interpreted as magnetite and intrusive with dominantly reversed-polarity remanent magnetization, weakly to moderately magnetic Precambrian crystalline basement, and magnetic Tertiary intrusions.
Precambrian Basement survey with the depth-to-magnetic source methods has been employed for several decades. The conceptualization is that principal anomalies in the observed magnetic field are produced by sources near the basement top [3]. There are numerous proven techniques, both manual and automated, that provide calculations of the magnetic source depth solutions [4]. Different techniques work best for dissimilar simplified source geometries like thin dike, sphere, contact, vertical or horizontal cylinder, etc. 2D Werner deconvolution and 3D Euler deconvolution, work on profiles of magnetic data and their algorithms, use simplified source geometry approximations and different calculation parameters (structural index) to solve a system of redundant equations for magnetic source parameters, depth and location. The two complicating factors are anomalies' interference, noise contamination, igneous intrusions penetrating deeply into the sedimentary section and, often, sparse distribution of "reliable" depth solutions that make accuracy and lateral resolution of the basement interpretation below expectations of the modern oil and gas exploration in structurally complex areas. 3D modeling and structural inversion are based on construction of 3D magnetic model of subsurface from available data that is inverted for the basement depth. The working concept is that the model misfit (i.e. difference between the observed magnetic field and that of calculated from the constructed 3D model) can be assigned to unknown variations of the basement depth and, hence, inverted for it. The precision and lateral resolution of 3D structural inversion is robustly reliant on information about magnetic susceptibility of basement rocks and the initial basement structure chosen. Such information is, usually, very limited or not available. [5-8] use ground and aeromagnetic dataset primarily in unmasking character of the subsurface particularly in geological mapping and mineral prospecting in areas with finite. 
Large scale aeromagnetic surveys are conducted in the study area to locate faults, fractures, shear zones that could host mineralization and also used for guidance exploration for epigenetic and stress related mineralization in the country rocks. In other to contribute to our understanding of the structural dynamics and economic mineral potentials of this part of the Precambrian basement terrain of Akure region, necessitated the use of aeromagnetic survey to delineate the surface and subsurface structures which control the anomalous mineralization in the area. In this research, analytical signal, reduction to equator, derivatives, spectra and Euler deconvolution were used to analyze and interpret total magnetic field data in providing enhanced understanding of the structural architecture and geologic model of the study area.

\section{LOCATION AND GEOLOGIC SETTING}

Akure is a city in South-Western Nigeria and is the largest city and capital of Ondo State. The area lies within latitude $07^{\circ} 10 \mathrm{~N}^{\prime}$ to $07^{\circ} 20^{\prime} \mathrm{N}$ and longitude $005^{\circ} 00^{\prime} \mathrm{E}$ to $005^{\circ} 17^{\prime}$ East South Western Nigeria [9]. The study area is situated on a rugged and gentle undulating terrain. The area lies within the South Western portion of Nigeria's Precambrian basement complex (Figure 1) which lies within Pan African mobile belt, East of West African Craton.

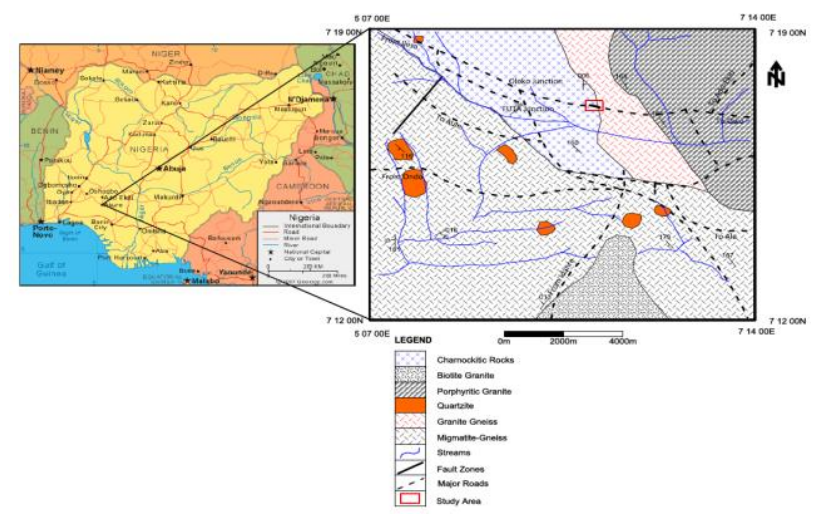

Figure 1: Simplified geological map of Akure, showing the study area (Modified after Owoyemi, 1996); Left: Administrative map of Nigeria.

About two-third of Nigeria's land mass is underlain by the Precambrian basement complex [10]. The crystalline rocks in Nigeria are made up of the Precambrian Basement Complex and Phanerozoic rocks. Consequently, NE-SW, NW-SE, NNE-SSW, NNW-SSE and to a less extent E$\mathrm{W}$ fractures have developed $[11,12]$

The area under investigation Akure and its environs which is situated in the Southwestern part of the Precambrian Basement Complex of Nigeria The Precambrian Basement of Nigeria has been classified into four major groups or division on a tectono-stratigraphic basis. These major rock groups consist of the Gneiss-Migmatite Quarzite Complex, the schist belts, the Pan African Granites (older granites and associated granitoids) and minor felsic and mafic intrusive [13]. Geological and geophysical mapping over the years in Akure area showed that some of the crystalline rocks present have been tectonically disturbed which have led to the development of several structures such as folds, faults, fractures, cavities and depressions [14]. The use of aeromagnetic study in the area supports its classification as a highly mineralized zone $[15,16]$. Akure falls within the Southwestern portion of Nigeria Precambrian Basement Complex which lies within Pan African mobile belt, East of West African Craton. The Basement complex is polycyclic and underlain by basement rock types (slightly migmatite gneiss complex rocks that are slightly migmatised to non-migmatite metasedimentary and meta-igneous rocks, charnokites and granite rocks) while the top soil ranges from sandy clay to dark loamy soil and gravel aggregates.

The charnockitic rocks of Akure intruded into the Gneiss-MigmatiteQuarzite complex and the older granite suite. Dykes are also associated with the Gneisses and older granites occurring in tabular, unmetamorphosed bodies cross cutting the foliation in the host rock and are regarded by Rahaman [10] as the youngest member of the basement complex. They range in thickness from about a few millimeters to half a meter. They trend North-East and South-West and East North-West to West South-West [17]

The major rock types in the area as classified by:

(a) The gneiss-migmatite-quartzite complex; (b) The schist belts which are low to medium grade supracrustal and meta-igneous rocks;(c) The Pan African granitoids (Older Granites) and other related rocks such as charnockitic rocks and syenites; and (d) Minor felsic and mafic intrusive.
These rocks occur as inselberg, isolated and continuous hills. Low lying outlying outcrops of magmatite gneiss and quartzite boulders were also seen in the study area [18]. The Charnockitic rocks have experienced deformation and were said to be (a) younger than the granitic rocks, (b) of the Pan-African age and (c) of igneous origin [9]. The charnockitic rocks contain plagioclase, biotite, quartz, hornblende, muscovite and orthoclase as major minerals while zircon is accessory with modal composition of $32 \%, 16 \%, 16 \%, 16 \%, 11 \%, 5 \%, 3 \%$ respectively. It is also believed that the charnockitic rock is of a sedimentary parentage noting that the magma from which it was emplaced might have been generated from the sediments that were deposited in the basins from which the nearby IfeIlesa schist belt was formed. A scholar reported that the porphyritic granite was emplaced earlier than the fine-grained hybrid and the charnockitic rocks [19]. The porphyritic granite consists of quartz, Kfeldspar, biotite, plagioclase, hornblende, pyroxene and mymerkite as major minerals. The average modal composition is $39 \%, 24 \%, 21 \%, 11 \%$ $3 \%, 2 \%$ and $1 \%$ respectively. Culling, the porphyritic granite (xenolith) consists of plagioclase, quartz, biotite, hornblende, mymerkite as major minerals and apatite as accessory. This porphyritic granite is generally plutonic in nature and are believed to be formed during the late crystallization of magma. They have a characteristic pinkish coloration; they are elliptical in shapes with megascopic biotite crystals. Some tend to be reddish because of garnet occurring in the granite.

Granite-gneiss covers about 45\% of the total study area, majorly they are trending approximately North-South and few of them are trending in EastWest direction, those trending approximately North-South are all dipping to the west. The gneisses display a N-S to NE-SW $\left(0-50^{\circ}\right)$ trending foliations with dips varying from $30-50^{\circ}$ towards $90^{\circ}$ and those with trending foliations of N-S to NE-SW $\left(100-180^{\circ}\right)$ respectively. The granitegneiss was seen prominently along with the south-western part to southeastern part of the study area. Its color varies from light to dark grey and it is usually medium to coarse grained with porphyroblastic texture. The minerals are oriented randomly and consist of Quartz, Biotite, Muscovite and feldspar with some trace elements like garnet which is coarse grained. There are quartz vein and pegmatite intrusion present. There is presence of light and dark bands within the rock which was a result of re-alignment of mineral during metamorphism. Thin section analysis revealed that plagioclase is the most abundant mineral within the rock followed closely by quartz. Grey-Gneiss is essentially gneissic with clear bands of alternating felsic and mafic minerals. The megascopic minerals include quartz, feldspar, biotite. The texture is from fine-medium and there are joints on the rock which run discordant to the foliation trend while some run concordant to the foliation orientation. They are seen within the granite-gneiss in the study area.

Pegmatitic rock classification is based purely on the size of its crystal Pegmatite bodies are thought to form predominantly, in granite during their final stage of solidification. The final fraction of mineral materials is high in water and often in elements such as fluorine and lithium. The pegmatite in this area is found to occur conformably with the host rock but they are commonly cross-cutting. The Quartz veins and lenses occur in all the major rock types of the basement complex and they are small varying in thickness from a few millimetres to a metre. They show great irregularities in their form and are seen in places to thin out widen or turn in their course. Dolerite dykes are also associated with the Gneisses and older Granites, occurring as tabular, unmetamorphosed bodies cross cutting the foliation in the host rocks and are regarded by a researcher as the youngest member of the basement complex. They range in thickness from about a few millimetres to half a metre. They trend northeast to southwest and east-northeast to west-southwest [20].

Several works have been done in the Akure and environs. Such works include a group of researchers who have given account of the geology of this area [21-23]. They note that the rocks in this region show evidence of polyphase deformation with the plutonic episode of the Pan African event being the most invasive. The southwestern basement complex of Nigeria lies within the rest of the Precambrian rocks in Nigeria, he grouped the rocks in this area as migmatite - gneiss complex comprising largely of sedimentary series with associated minor igneous rock intrusions which have been altered by metamorphic, migmatitic and granitic processes. A scholar suggests that almost all the foliation exhibited by rocks of southwestern Nigeria excluding the intrusive are tectonic in origin, because pre-existing primary structures have been destroyed bysubsequent deformation. The researcher also observes that joints ranging from minor to major ones are found in all the rock types, some of which are filled with quartz, feldspars or a combination of both which lie generally in the NE-SW direction, while the south western basement complex of Nigeria has been affected by two phases of deformation namely D1, D2, the first phase (D1) produced tight to isoclinals folds while the second phase (D2) is characterized by more open folds of variable style and large vertical NNE-SSW trending fault. Other scholar gives evidence 
that within the basement complex, tectonic deformation has completely destroyed primary structures except in a few places where they survived deformation [24].

\section{MATERIALS AND METHODS}

\subsection{Aeromagnetic data}

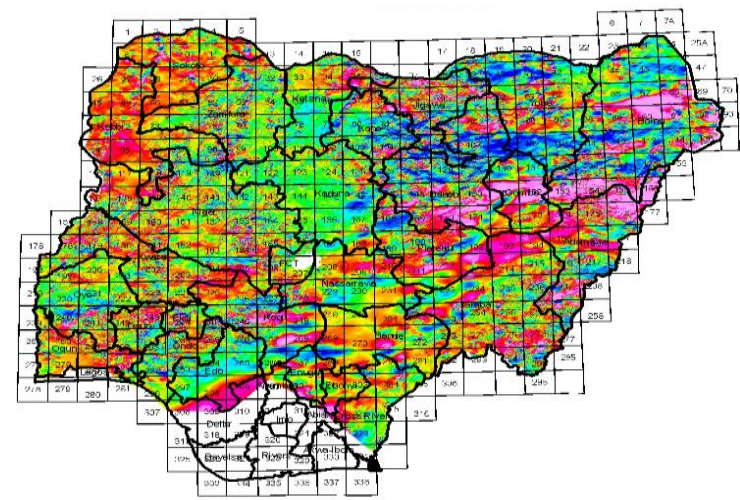

(a)
With the nationwide mandate of acquisition of high resolution airborne geophysical survey aimed at assisting and promoting mineral exploration in Nigeria, aeromagnetic data was acquired between 2003 and 2009 by Fugro Airborne Survey Limited for the Nigerian Geological Survey Agency (NGSA) (MMSD, 2010). The data was acquired systematically by dividing the country into geological blocks with divergent measurable parameters for each block with the eventual production of an aeromagnetic map for the whole country (Figures $2 \mathrm{a}$ and $\mathrm{b}$ ).

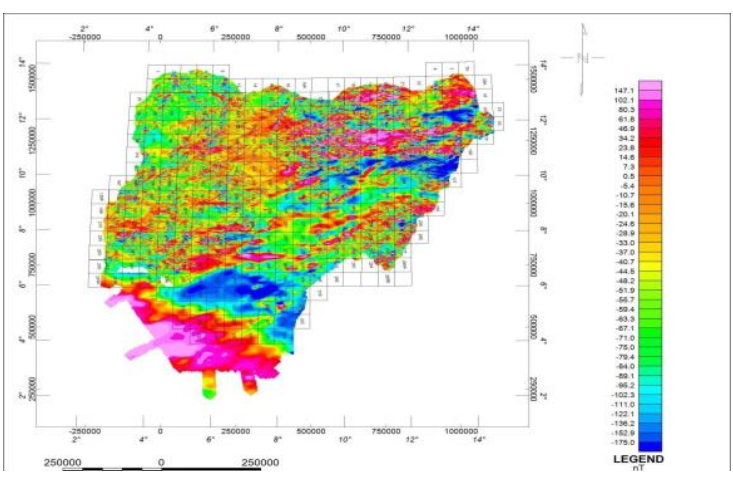

(b)

Figure 2: (a) Nigeria Magnetic Index map and (b)Nigeria Fixed- wing Airborne TMI Map (Superimposed federal Survey half Degree Sheets) Source: NGSA.

The following equipment specifications were used-Scintrex CS3 Cesium Vapor magnetometer, Data Acquisition System FASDAS, Magnetic Counter FASDAS, Radar Altimeter KING KR405/KING KR405B, Barometric Altimeter ENVIRO BARO/DIGIQUARTZ. Scintrex CS3 optically pumped Cesium Vapor magnetometer was used for scalar measurement of the Earth's magnetic field. It is highly sensitive and measures in the range of pT $(1 \mathrm{pT}=0.001 \mathrm{nT})$ in a measuring bandwidth of $1 \mathrm{~Hz}$ and this sensitivity does not deteriorate as the measured ambient field decreases. It measures between 15,000 $\mathrm{nT}$ and 100,000 nT.

Akure and its environs designated as Sheet 264; is part of Block B and was surveyed in Phase 1 of the project. The survey was carried out by fixed wing (Cessna) caravan -208B ZS-FSA, 208 ZS-MSJ, 406 ZS-SSC aircrafts covering a total of 235,000-line kilometers with a flight spacing of 200 meters and a terrain clearance of 80 meters. The flight direction was NWSE with tie-line spacing of 200 meters and tie-line direction of NE-SW. A recording interval of 0.1 seconds and a grid mesh size of 50 meters were applied in the World Geodetic System of 1984 (WGS84) within UTM Zone $36 \mathrm{~S}$, central median $33^{\circ} \mathrm{C}$ East, Central scaling factor 0.9996 and with the Spheroid Clark 1880/Arc 1960 coordinate system.

\subsection{Methodology}

\subsubsection{Vertical Derivatives}

Based on a study, vertical derivative (or alternatively named - vertical gradient||) filters preferentially amplify short-wavelength components of the field at the expense of longer wavelengths [25]. Vertical derivative filters are generally applied to gridded data using FFT (Fast Fourier Transform) filters. Various vertical derivatives of the magnetic field can be computed by multiplying the amplitude spectra of the field by a factor of the form (Eq. (1)):

$\frac{1}{n}\left[\left(u^{2}+v^{2}\right)_{2}^{1}\right]^{n}$

Where $n$ is the order of the vertical derivative. The first vertical derivative (or vertical gradient) is physically equivalent to measuring the magnetic field simultaneously at two points vertically above each other, subtracting the data and dividing the result by the vertical spatial separation of the measurement points. The second vertical derivative is the vertical gradient of the first vertical derivative and it is also commonly used as an aid to geologic mapping i.e. for the delineation of geological discontinuities in the subsurface. According to a scholar, first vertical derivative data have become almost a basic necessity in magnetic interpretation projects [26].

\subsubsection{Continuation of the field}

The amplitude of a magnetic field above a source varies with elevation as an exponential function of wavelength. This relationship can be readily exploited with FFT filters to re-compute the field at a higher elevation (upward continuation\|) or lower elevation (downward continuation (where $\mathrm{z}$ is positive downward). As described by a scholar, the process has a frequency response of

$e^{-h}\left(u^{2}+v^{2}\right)^{1 / 2}$

(where $h$ is elevation) (Eq. (2)). This means that upward continuation smooths out high-frequency anomalies relative to low-frequency anomalies. Downward continuation on the other hand sharpens the effects of shallow anomalies (enhances high frequencies) by bringing them closer to the plane of observation [27].

$$
F(x, y,-h)=\frac{h}{2 \pi} \iint \frac{F(x, y, 0) \partial x \partial y}{\left[\left(x-x^{\prime}\right)+\left(y-y^{\prime}\right)+h^{2}\right]}
$$

Where $F(x, y,-h)=$ Total field at the point $\mathrm{P}(\mathrm{x}, \mathrm{y}-\mathrm{h})$ above the surface of which $\mathrm{F}(\mathrm{x}, \mathrm{y}, 0)$ is known as $\mathrm{h}=$ elevation above the surface (Eq.(3))

\subsubsection{Analytic signal}

Analytical signal is a popular gradient enhancement, which is related to magnetic fields by the derivatives. A previous study showed that the amplitude of the analytic signal can be derived from the three-orthogonal gradient of the total magnetic field using the expression [28]:

$|A(x, y)|=\sqrt{\left(\left(\frac{\delta m^{2}}{\delta x}\right)+\left(\frac{\delta m^{2}}{\delta y}\right)+\left(\frac{\delta m^{2}}{\delta z}\right)\right)}$

where $A(x, y)$ is the amplitude of the analytical signal at $(x, y)$ and $m$ is the observed magnetic anomaly at (x,y). While this function (Eq. (4)) is not a measurable parameter, it is extremely interesting in the context of interpretation, as it is completely independent of the direction of magnetization and the direction of the Earth's field [29]. This means that all bodies with the same geometry have the same analytic signal.

\subsubsection{Semi automated methods}

(1) Werner deconvolution

According to a study, the idea of introducing this polynomial was adopted from the famous Werner deconvolution [30,31]. This method is built on the recognition of the anomalous effect of a dike in the profile magnetic field $\Delta \mathrm{T}$, (Eq. (5)). The introduction of a polynomial of higher degree, together with the magnetic field, in the interpretation equation (Eq. (6)), helped to improve the stability and clustering of the solutions. The Werner deconvolution function (which uses the horizontal and vertical derivatives in the calculation in the depth to basement of the magnetic anomaly was employed. It assumes the source bodies are either dikes or contacts with infinite depth extent and uses a least-squares approach to solve for the source body $[32,33]$. 
$\left(x-x_{0}\right) \frac{d f}{d x}+\left(y-y_{0}\right) \frac{d f}{d y}++\left(z-z_{0}\right) \frac{d f}{d z}=-N f$

$\left(x-x_{0}\right) \frac{d f}{d x}+\left(y-y_{0}\right) \frac{d f}{d y}++\left(z-z_{0}\right) \frac{d f}{d z}=N f+A_{0}+A_{1 x}+A_{2} y+$ $A_{3} x y+A_{4} x^{2}+A_{5} y^{2}+A_{6} x^{2} y+A_{7} x y^{2}+A_{8} x^{3}+A_{9} y^{3}+\cdots$.

(2) Euler Deconvolution

According to a study, Euler derived interpretation is not confined by any geological preconception and can be used to appraise geological and structural interpretation [34]. It also needs only a little prior knowledge of the magnetic source geometry and information about the magnetization vector [35]. If a total field (T) measured at a point (X, Y, and Z) has a base level of $b$ and derivatives $(d T / d x, d T / d y$ and $d T / d z$ in the $X i, Y i$, and $Z i$ direction), the 3-D form of Euler's equation is defined by a scholar as [36]:

$\frac{X d T}{d x}+\frac{Y d T}{d y}+\frac{Z d T}{d z}+\pi T=\frac{X o d T}{d x}+\frac{Y o d T}{d y}+\frac{Z o d T}{d z}+\pi b$

$\frac{(x-x o) d T}{d X}+\frac{(y-y o) d T}{d y}+\frac{(z-z o) d T}{d Z}=\pi(b-T)$

Extended Euler deconvolution was recently implemented by a scholar following the methods of other scholars [37-39]. Euler deconvolution method analyses large quantities of data, requiring automated methods of estimating depth to basement, a group of researchers obtains its solutions by inverting Euler's homogeneity equation over a window of data at every grid point [40].

In this study, we used the Euler deconvolution algorithm using Oasis Montaj $^{\mathrm{TM}}$ for location and depth determination of causative anomalous bodies from gridded aeromagnetic data was used. The map thus produced shows the locations and the corresponding depth estimation of geologic sources. Also, Extended Euler deconvolution was carried out to determine the depth to the magnetic basement from profiles at estimated level of certainty. Table 1 shows the summary of the structural indices for simple models in magnetic field. This contribution focuses on the classical algorithm, where the value of $\mathrm{N}$ is assumed to be known, but various approaches on how to get its value directly during potential field data interpretation also exists $[41,42]$.

The derived solutions were further buffed by using the Minimum window size, since the maximum width of anomaly expected is based on field observation is around $250 \mathrm{~m}$ and this value will ensure that a solution point constitutes a single anomaly point [43]. Generated solutions were windowed to plot only solutions that are within acceptable limit as a measure to further reduce spurious results.

\subsubsection{Power Spectrum}

In this study, we used power spectrum analysis to carry out on aeromagnetic data using Geosoft ${ }^{\circledR}$ Oasis Montaj ${ }^{T M}$ software to identify average depths of source assemblage. Each wavelength's power unit was plotted against wavenumber regardless of direction, to produce a power spectrum. In frequency domain, we prepare and analyze the distribution of short to long wavelength across all measured high to low frequency. The power spectrum was broken into series of straight lines segments and each segment represents the cumulative response of a discrete assemblage of sources at a given depth. According to a study, the depth is directly proportional to the slope of the line segment [44]. Potential field may be considered as representing a series of interfering waves of different wavelengths and directions.

The slope of each segment provides information about the depth to the bottom of the magnetic bodies [45]. Radially averaged power spectrum of magnetic data according to is expressed as a function of wavenumber and
Equations 7 and 8 is 3 -d Euler equation, where $\eta$ is the structural index (SI) defined as the degree of homogeneity of the source body interpreted physically as the attenuation rate with distance. Its value needs to be chosen according to earlier knowledge of the source geometry (Table 1) $\mathrm{b}$ is the background value of the field while Xo, Yo, and Zo is the position of a source whose total field $\mathrm{T}$ is detected at any point.

Table 1: Summary of the structural indices for simple models in magnetic field.

\begin{tabular}{|l|l|l|}
\hline $\begin{array}{l}\mathrm{N} \text { use in } \\
\text { Magnetics }\end{array}$ & $\begin{array}{l}\text { Number of infinite } \\
\text { dimensions }\end{array}$ & $\begin{array}{l}\text { Elementary body model } \\
\text { (source type) }\end{array}$ \\
\hline 3 & 0 & sphere \\
\hline 2 & $1(\mathrm{z})$ & Pipe (vertical cylinder) \\
\hline 2 & $1(\mathrm{x}-\mathrm{y})$ & Horizontal cylinder \\
\hline 1 & $2(\mathrm{z}$ and $\mathrm{x}-\mathrm{y})$ & Dike (sheet) \\
\hline 1 & $2(\mathrm{x}$ and $\mathrm{y})$ & sill \\
\hline 0 & $3(\mathrm{x}, \mathrm{y}$ and $\mathrm{z})$ & contact \\
\hline
\end{tabular}

is related to depth to the bottom of the deepest sources as expressed in equation $9[46]$.

$-K_{\max }=\frac{\log Z b-\log Z t}{Z b-Z t}$

Where $\mathrm{Zt}$ and $\mathrm{Zb}$ are depth to top and depth to bottom of the magnetic sources respectively. $\mathrm{K}$ is a function of wavenumber which is expressed in radian per unit distance.

\section{RESULTS AND DISCUSSION}

\subsection{Residual Magnetic Anomaly}

The RMI map displays different regional magnetic zones (A, B, C, D-D', E and E' in Figure 3a), with most of them trending in the NE-SW direction. The magnetic zone division was based on the intensity, shape, and pattern in magnetic signatures. At the western lower corner, there exists a high magnetic signature zone A (Figure $3 \mathrm{a}$.) which is cut by lower magnetic signature B (Figure 3a). This feature trends almost in the South- North direction. From the RMI image, the high magnetic susceptible body, A, observed at the lower left corner of Figure 3a; are suspected to be due to near surface magnetic minerals such as crystalline rocks (igneous or metamorphic) with an observed shallow sources like igneous or metamorphic rock [47]. This intruding body B that cuts the A body is suspected to be an indication of an intrusion due to complex sources consisting of closely spaced anomalous bodies [48]. A network of lineaments suspected to be fracture zones whose trends are generally in the Southeastern and Northeastern and the magnetic response showed varying intensities in magnetite content of the underlying rocks in Akure area [48]. This feature consisting of several closely spaced anomalous bodies of low magnetic signatures at the Southeastern and Northeastern parts $\left(\mathrm{C}, \mathrm{D}, \mathrm{D}^{1}\right.$ in Figure $3 \mathrm{a}$.) of the area has its high magnetic intensities ranging from $(87.4 \mathrm{nT}-114.6 \mathrm{nT})$.These features $\left(\mathrm{C}, \mathrm{D}, \mathrm{D}^{1}\right)$ are suspected to be due to the depletion of magnetite content or oxidation/maghemitization of primary titanomagnetite has been interpreted to be the main cause of decrease in NRM intensity with increasing age of MORB, concomitant with increasing distance from spreading ridges $[49,50]$. Additionally, the most prominent relatively high magnetic intensity (96.7nT-114.6) with a polygon feature is observed at the top left corner, Northwestern zone E (Figure 3a) of the area with some inflection points of high magnetic signature ( $\left.\mathrm{E}^{1}\right)$.

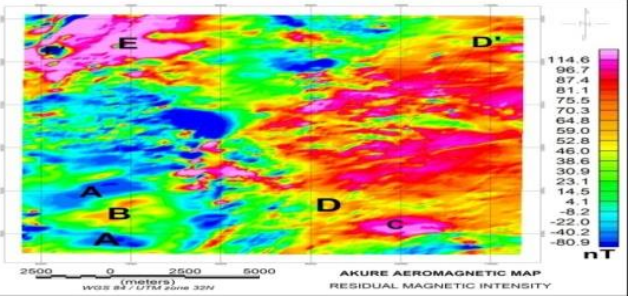

(a)

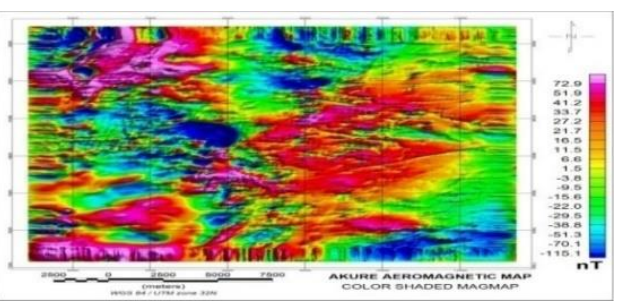

(b)

Figure 3: (a) Residual magnetic intensity Aeromagnetic Map of Akure and (b) Magmap Gridded Aeromagnetic Map of Akure. 
At some places on the residual map there are anomalies that are not present on the total magnetic intensity map (Figures $3 \mathrm{~b}$ ) due to the subtle magnetic anomalies observed after residualization. Summarily, the 2D RMI map of Akure (Figure 3a) revealed that the area is magnetically heterogeneous. According to a study, areas of very strong magnetic values may likely contain outcrops of crystalline igneous or metamorphic rocks, deep seated volcanic rocks or even crustal boundaries [51]. The areas with low magnetic signatures are suspected to contain near surface magnetic source rock such as: sandstones, near-surface river channels and another near-surface intrusive with magnetic low intrusive.

\subsection{Reduction to Equator Map}

Reduction to equator, RTE filter was applied to the RMI grid to locate the observed magnetic anomalies directly over the magnetic source bodies that caused the anomaly. It was also applied to remove the influence of magnetic latitude on the residual anomalies. The RMI grid was transformed into reduction to the pole (RTE) grid using the 2D-FFT (Fast Fourier Transform) filter in Geosoft Oasis Montaj software. The parameters used for the transformation are an inclination of -11.10 and declination of -4.90 which represent the mean value for the area. The RTE magnetic anomaly map (Figure 4) shows both low and high magnetic frequencies representing points of low and high magnetic signatures respectively in the area. We used the Fourier domain technique, which enhances anomalies with specific orientation and subtle, yet important inclination needs to be revealed but are obscured and complicated by lineaments in other directions. This approach aided us to estimate gradient in the direction of greatest rate of change and the trend. Since the angle of the output grid tends to zero in equatorial belt then $\mathrm{dx}$ is the gradient to the east and dy is the gradient to the north. In figure. 4 the EW striking features are clearly defined at the magnetic equator. Both RMI (Figure 3) and the reduction to the equator RTE image (Figure 4) display similar magnetic features, but in the RTE image the highs (pink colour) of the RMI are lows (blue colour). The RTE map shows more significant features such as structures and lithology in the magnetic signature than the residual magnetic intensity map. At the Eastern Zone A (Figure 3) some features observed in the RMI are now seen as linear features trending in the North-South direction. Moreover, other features (e.g. the low magnetic signature B (Figure 3) and high magnetic signature (Figure 4) which are not clearly seen in the RMI image (Figure 3) are seen in the RTE. Also observed are some high (pink) features in the RMI image remained high (pink) in the RTE image. Example is the magnetic signature (A) found at the Eastern part of the area. This region may represent very shallow basement, in accordance to what a scholar reported [52]. The RTE image displays the highest magnetic intensity at the Eastern part of the area (A) (Figure 4) with the average peak to peak at about 170nT. These high magnetic anomalies are seen to trend in the NW-SE direction. Clear lithological boundaries are also observed in the image. These boundaries are observed from the sharp contrast in the magnetic signature on adjacent magnetic bodies. The sharp change in magnetic signature from high amplitude anomaly to low amplitude anomaly which exhibited as narrow boundaries which were not seen clearly on the RMI grid are inferred fault zones. (F-F1, S-S'). Some magnetic contrasts observed in Figure. 4 are interpreted as the lithological contacts.

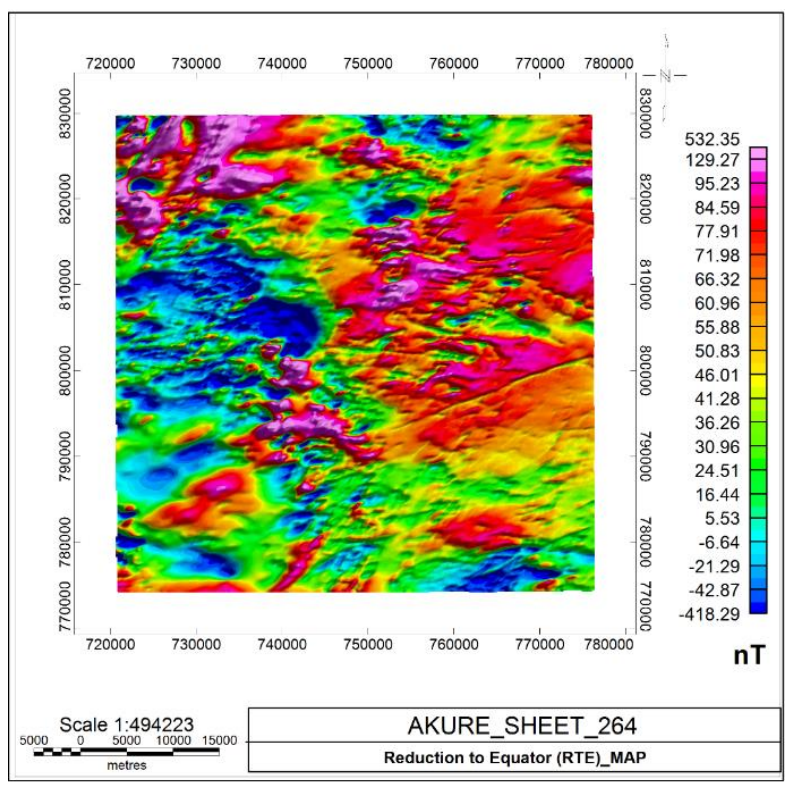

Figure 4: The Reduction to Equator of the Aeromagnetic data of Akure

\subsection{Continuation Map}

Figure. 5 shows the upward continuation of the RMI map. From the upward continuation map, it is seen that the boundaries of the different formations are well demarcated and the features that are present are well enhanced and the entire map is distinct compared to the downward continuation (Figure. 6). The upward continuation map enables the easy observation of long wavelength anomalies not seen in the original RMI Map. From this map structural interpretations were carried out through visual inspection, because of the small mineralized bodies in the study area. Eight of the long and short wavelength high amplitude anomalies $\mathrm{A}$ B, C, D and E (Figures 5 and 6) have no similar trend (approximately EastWest) with prominent anomalies A, B and C (44.5 nT - 175.4 nT). For instance, F1 -F1 represents lineaments in the study area.

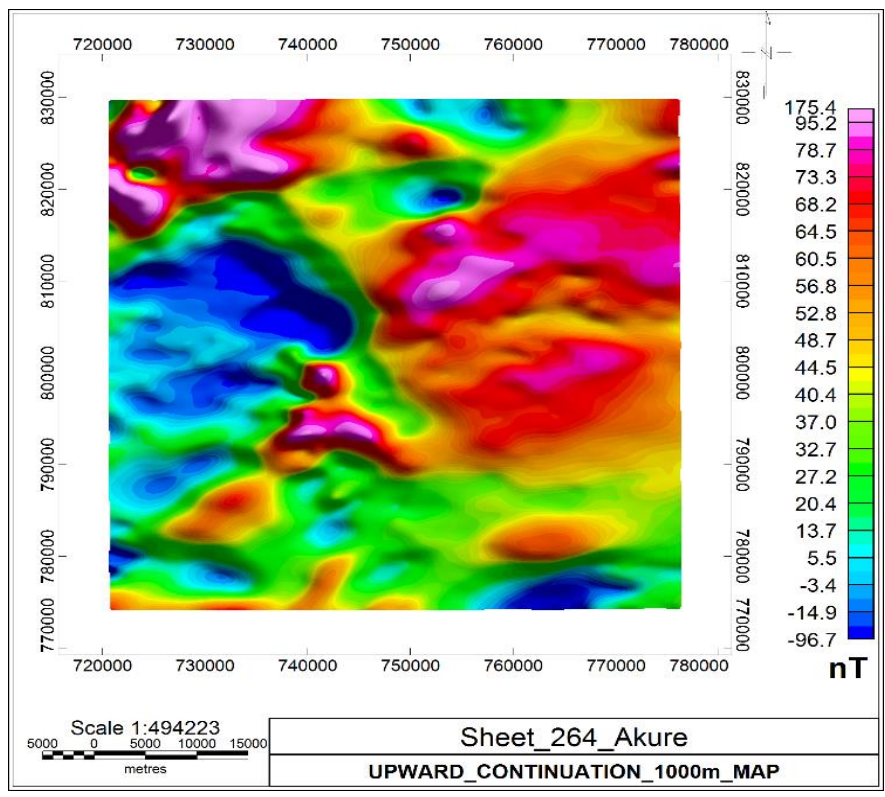

Figure 5: RMI Map being Continued Upward to 1000m.

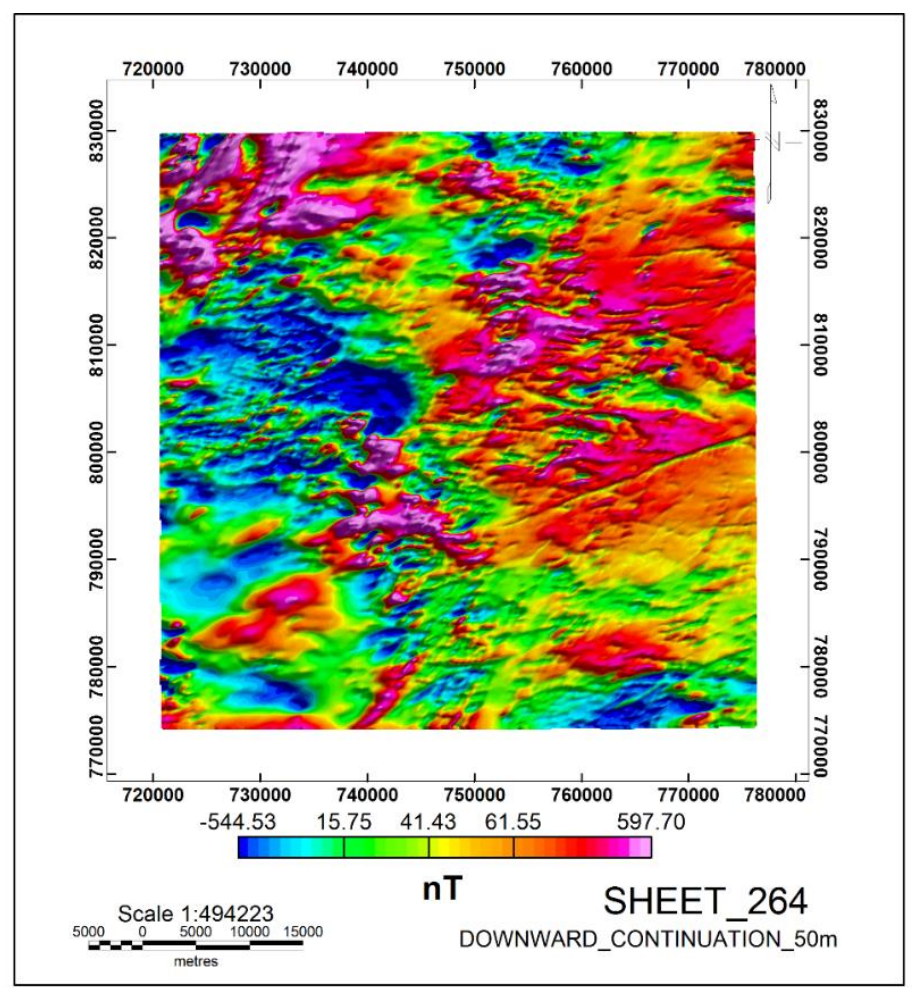

Figure 6: RMI Map being Continued Downward to 50m

\subsection{The Analytical Signal Contour Map}

Analytic function is extremely interesting in the context of interpretation, in that it is completely independent of the direction of magnetization and direction of the earth's magnetic field. This means that all bodies with the same geometry have the same analytic signal. An important goal of data processing is to simplify the complex information provided in the original data and such simplification is to derive or generate a map on which the 
amplitude of displayed function would be directly and simply related to a physical property of the underlying rocks. Analytic signal isolates weak anomalies resulting from the subdued magnetic sources occurring within strata and is related to the amplitude of magnetization [53]. The analytic signal contour map (Figure 7) allows us to identify and map near-surface magnetic minerals somewhat more readily.

Analysis of the analytic signal (Figure 7) reveal N-S structures which are challenging to identity in the equatorial belt and confirmed the existence of bounding structures such as lineaments /or rock contacts in the study area i.e. displayed as anomaly peaks. The 2D analytic signal Map of Akure (Figure 7) revealed near-surface anomalies whose magnitude ranges between $0.000 \mathrm{nT}$ and $0.092 \mathrm{nT}$ (Blue-yellow) being dominant in the area in terms of distribution. Those anomalies whose magnetization varies between 0.092nT and 2.199nT (burnt yellow-pink) which are displayed as anomaly peaks are observed in the North- south and some in scanty manner but occupying reasonable parts of the study area around northwest, North and central parts. Sharp peaks are indicators of shallow sources while broad peaks indicate deep seated or magnetic minerals of very large areal extent. The anomaly around these areas to be a shallow source is very high [54]. Moreso, anomaly peaks ranging between $0.080 \mathrm{nT}$ and $0.160 \mathrm{nT}$ (blue- yellow) are observed in dispersed form throughout the study area while three different locations within the study area (Southeast, Southwest and northeastern part) are anomalously low value magnetic anomalies that ranges $0.000 \mathrm{nT}$ and $-0.026 \mathrm{nT}$ (sky blue). These areas are suspected to be occupied by a deep-seated magnetic body, weak magnetic bodies or a magnetic body or large area of extent.

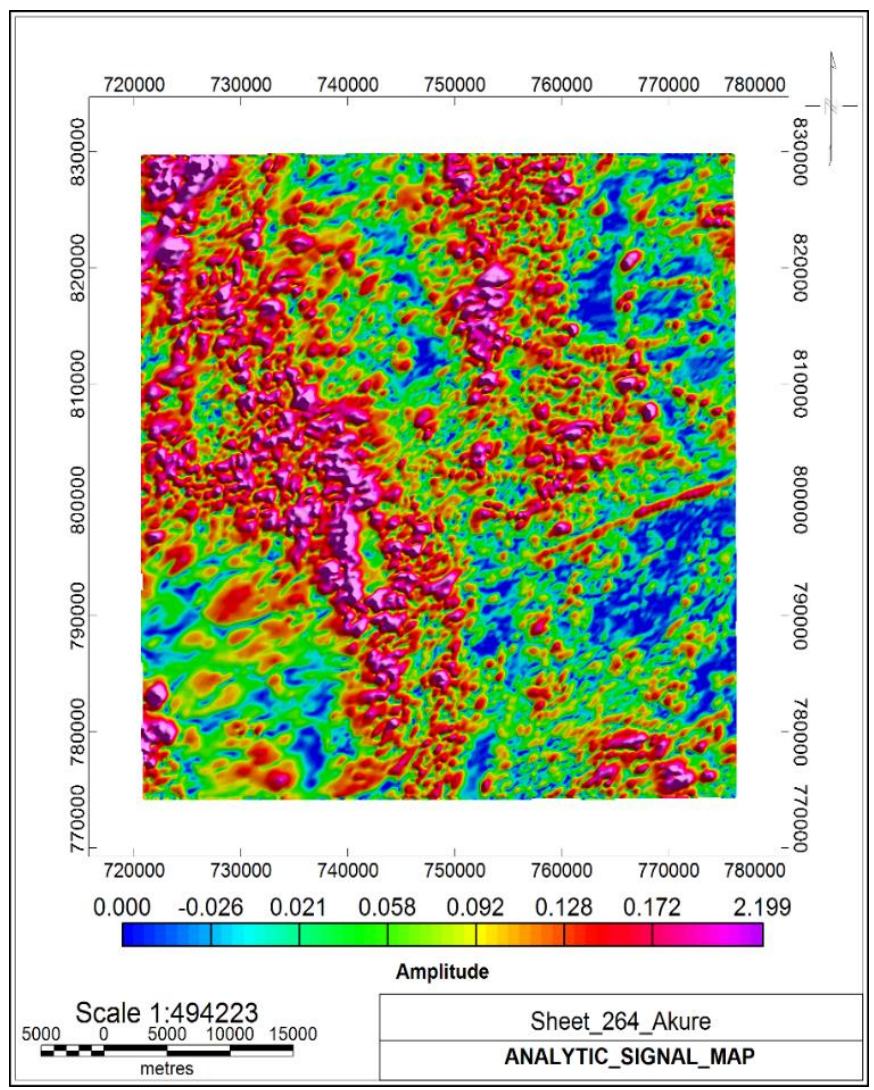

Figure 7: Analytical Signal Image of Residual Magnetic Intensity (Redpurple: high magnetic signature and blue- low magnetic signature)

\subsection{First vertical derivative}

The basement Architectures/structures are evident as shear zones, fault (brittle faults and domain fault boundaries) which are usually weak zones. First vertical derivative (Figure.8) reveal these basement structural features are usually subtle lineaments. They are gradient zones, alignment of separate local anomalies of several types and shapes, aligned breaks or discontinuities on the anomaly pattern. Subtlety of desirable lineament requires detail processing using a wide range of anomaly enhancement technique and display parameterization of filters. Filtering and image processing of aeromagnetic data are important technique in mineral exploration. Directional vertical derivatives narrow the width of anomalies and so locate the source bodies more accurately [55].

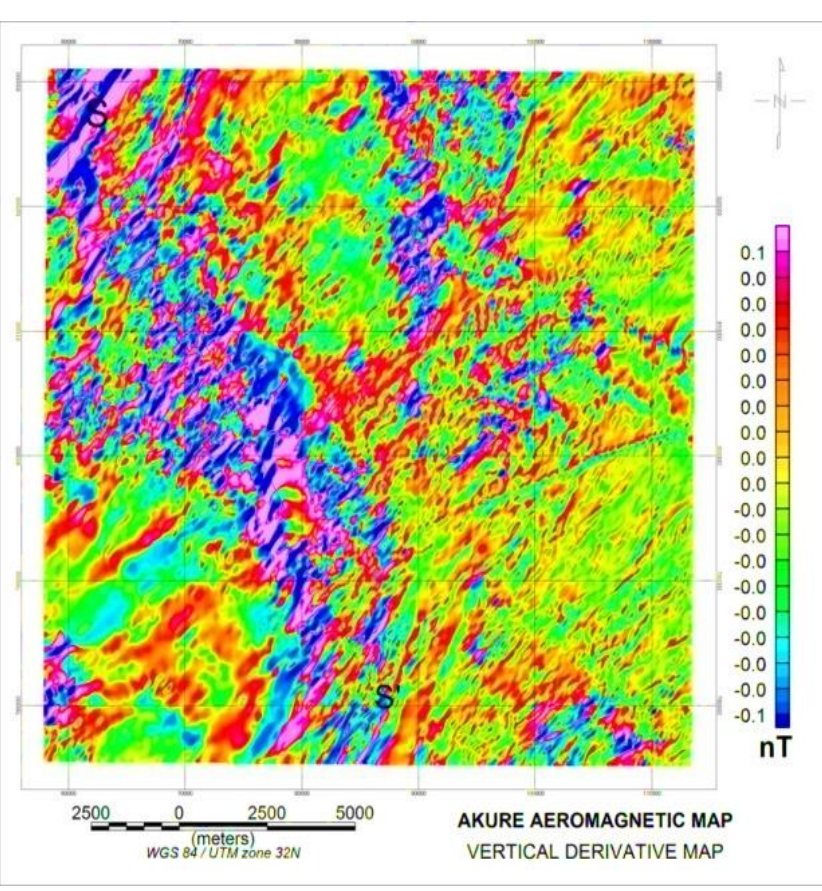

Figure 8: The First Vertical Derivative Map of the RMI grid.

\subsection{Depth estimation}

\subsubsection{The Radial Spectrum Plot}

Attempt was made to estimate the depth to basement of the magnetic body. The Geosoft Oasis montaj Depth to Basement extension which determines the position (distance along the profile and depth), dip (orientation) and intensity (susceptibility) of magnetic source bodies for a magnetic profile was used. The depths to the top of geologic sources that produced the observed anomalies in the aeromagnetic map were determined using spectral analysis $[56,57]$. The radially average power spectrum (Figure 9) of the Akure aeromagnetic data shows a normal plot that has straight line segments which decreases in slope with increasing frequency (Radial Spectrum). Deep seated and or magnetic sources of large areal extent are observed along profiles. These could also be associated with deep faults, deep seated volcanic rock or igneous rock. The very sharp anomaly peaks observed along profiles could be attributed to the outcrops of crystalline igneous and/or metamorphic rock or even exposed volcanic rocks. Other anomalies observed as revealed on the profile are probably due to the presence of near-surface magnetic minerals.

The depth to the magnetic source(s) along the profiles in the study area was found to range between $3.0 \mathrm{~km}$ to $11.0 \mathrm{~km}$, with an average depth of $7.0 \mathrm{~km}$ for the entire study area which agree with the results of similar previous works in and around the study area. The depth contour map (Figure 9b) showed that the depth is increasing towards the Eastern part of the map and decreases outwardly.

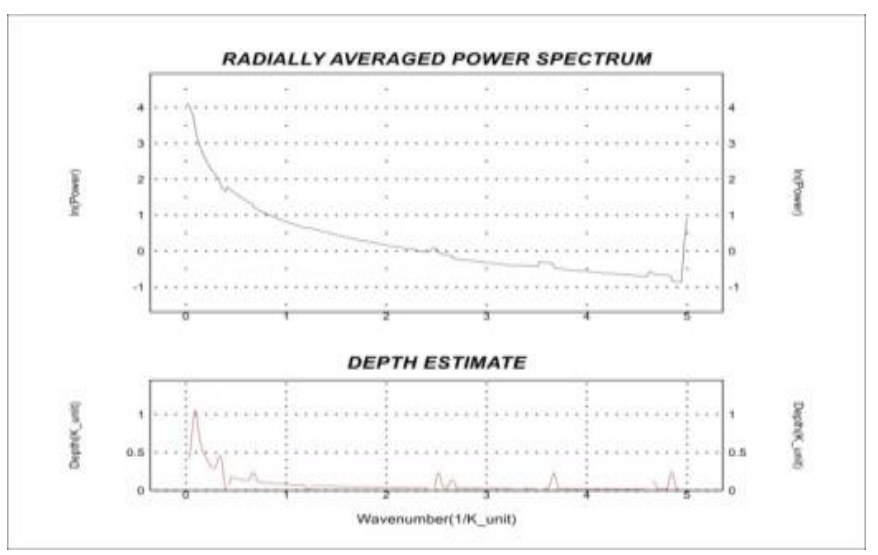

(a) 


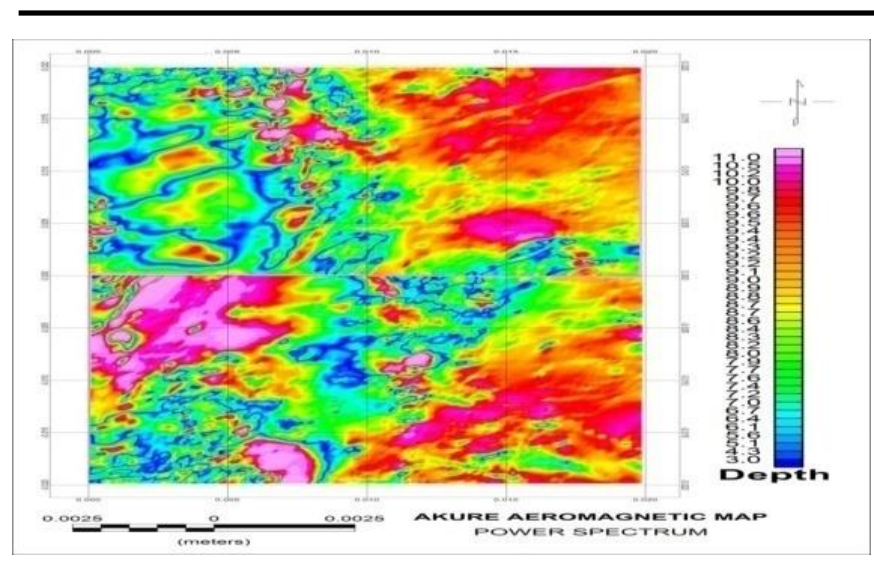

(b)

Figure 9: (a) The Radial Spectrum and Depth Estimate Plot of the Aeromagnetic and (b) Power Spectrum map of the Aeromagnetic data of Akure.

\subsubsection{Werner Deconvolution Profile Interpretation of Aeromagnetic Grid Lines 1, 250 And 558}

Three profiles were chosen across the aeromagnetic grid lines of the area to estimate the depth to magnetic bodies and magnetic intensity (susceptibility), namely Lines 1, 250 and 558 (Figure 10a, b and c). Two depth source models (Dike and contacts model) were assumed and their depths to basement were estimated using the Werner deconvolution function.

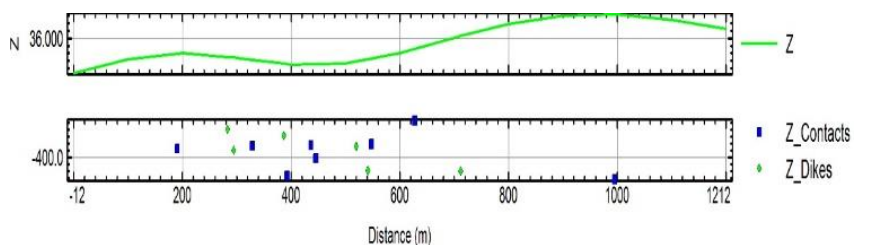

(a)

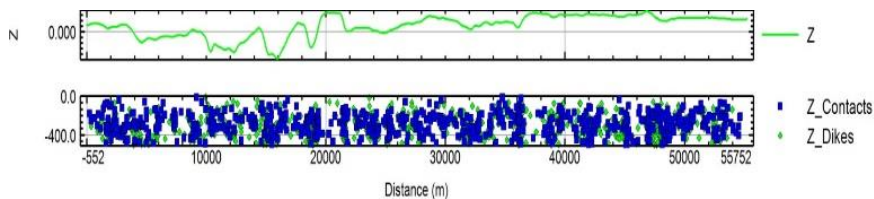

(b)

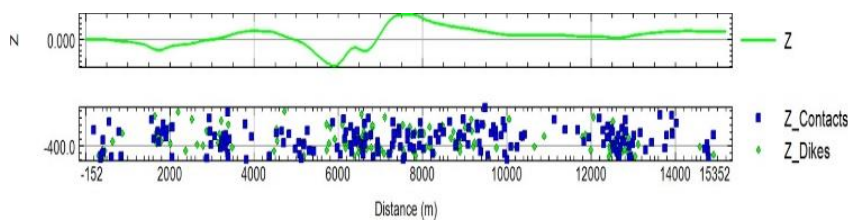

(c)

Figure 10: (a) Werner deconvolution solutions from aeromagnetic grid line (1) in the study area (b) Werner deconvolution solutions from aeromagnetic grid line (250) in the study area (c) Werner deconvolution solutions from aeromagnetic grid line (558) in the study area.

Aeromagnetic Grid Line 1(Figure 10a) Figure. 10a shows a profile whereby 14 solutions were generated with the dike model and the model for the contact generated 6 and 8 solutions respectively. The depth to basement of Line 1 ranged from approximately $20.6 \mathrm{~m}$ to $650.3 \mathrm{~m}$ and the magnetic anomaly values varied from approximately $8.0 \mathrm{nT}$ to $81 \mathrm{nT}$. The depth to basement of the dike model was shallow (approximately $150 \mathrm{~m}$ to $553.6 \mathrm{~m}$ ) as compared to the contact model (approximately $20.6 \mathrm{~m}$ to 650.3 $\mathrm{m})$.

\subsubsection{Werner deconvolution Profile Interpretation Aeromagnetic Grid Line 250 (Figure 10b)}

Figure $10 \mathrm{~b}$ shows a profile with numerous solutions were generated for the dike and contact model. The profile covered distance $-552 \mathrm{~m}$ to $55752 \mathrm{~m}$. The depth to basement of the profile ranged from approximately $0.0 \mathrm{~m}$ to $514.3 \mathrm{~m}$ with the magnetic anomaly values varying from approximately $-0.2 \mathrm{nT}$ to $1.0 \mathrm{nT}$. The depth to basement of the dike model was almost at the same depth range.
4.6.4 Werner deconvolution Profile Interpretation Aeromagnetic Grid Line 558(Figure 10c)

Figure 10c shows a profile whereby solutions were generated with the dike model and the contact model for the solutions. The depth to basement of Line 558 ranged from approximately $25.0 \mathrm{~m}$ to $533.4 \mathrm{~m}$ and the magnetic anomaly values varied from approximately $-0.0 \mathrm{nT}$ to $1.0 \mathrm{nT}$. The depth to basement of the dike model was shallower (approximately $50 \mathrm{~m}$ to $500 \mathrm{~m}$ ) as compared to the contact model (approximately $25.0 \mathrm{~m}$ to $533.4 \mathrm{~m}$ ).

\subsubsection{D Euler Deconvolution}

Figure. 3 shows the map of the derivative grids of the aeromagnetic data of the study area. These maps are required for the calculation and subsequent display of the analytical signal grids (map) shown in Figure 5 which is needed to perform the located Euler deconvolution adopted for this study. The analytical signal map (Figure7) is also useful in the location of edges of magnetic source bodies particularly were remanence and / or low magnetic latitude complicates interpretation.

The Euler deconvolution maps (Figure 11) present the derived source positions as circles at their plan positions with depth proportional to diameter. They show roughly the same trends at all three structural indices, but with different degrees of clustering and different depths. The Euler solutions were obtained for structural index values of $0.5,1.0$ and 2.0 Sources are characterized by their structural indices, which correspond to the rate of decay of the field strength with distance from the source [56]. The common accepted structural element in the study area is fault / or fracture and magnetic contact.

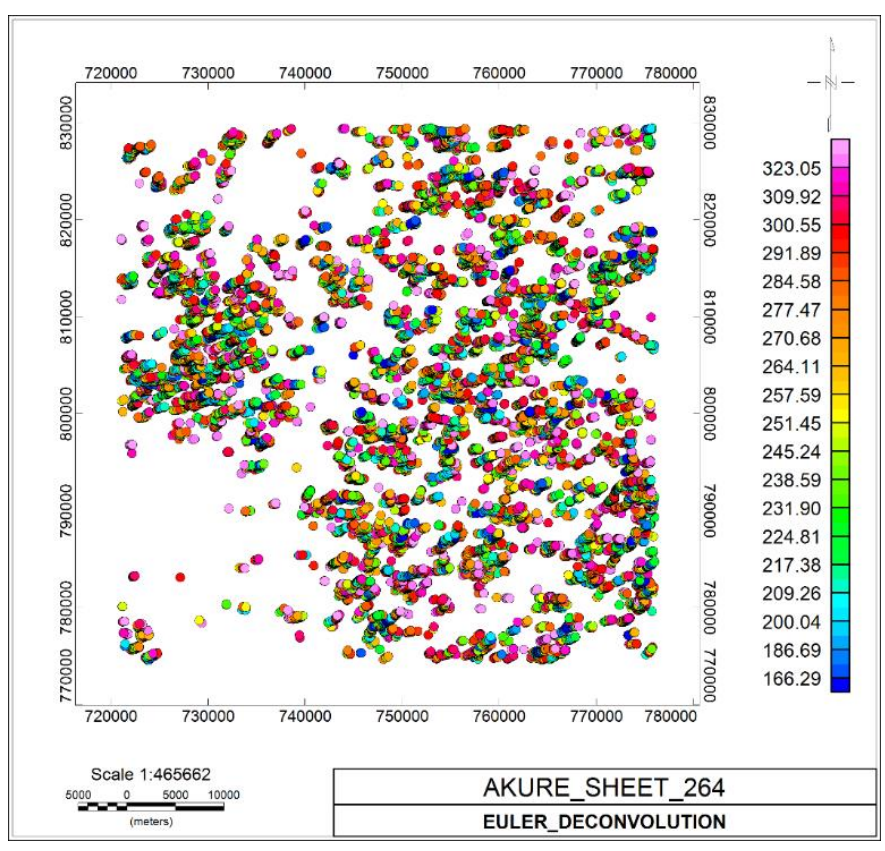

Figure 11: Result of Euler Deconvolution of Aeromagnetic Data acquired over the Study area.

\section{CONCLUSIONS}

Aeromagnetic method has been used to investigate the locations and depths of magnetic rocks in Akure, Southwestern Nigeria. A multidimensional approach to the studies (that is the magnetic Intensity map, residual 3-D map and Analytical signal, upward continuation, vertical derivative, Radial spectrum, Werner Deconvolution and Euler Deconvolution) has made the study both very qualitative and quantitative as information missed by any of the approach is revealed by the other and thereby necessitating justifiable conclusions. The analytic signal technique showed superior efficiency and accuracy in that, it has proved to be an excellent and versatile tool in its ability to reveal the magnetization levels of various concealed magnetic bodies, the source locations, their estimated depths and other complex geological structures. The results obtained from both profiling curves and depth contour map showed that the study area is magnetically heterogeneous, and the basement is segmented by faults. The results generated have shown the distribution, location and depth of mineral rocks in the study area. Magnetic basement and sedimentary cover have recognizable differences in magnetic source geometries as represented by distributions and alignments of depth solutions, obtained by application of 2D Werner deconvolution and 2D Euler deconvolution techniques. The empirical set of criteria, "basement indicators" has been 
developed for identification and correlation of the magnetic basement horizon. This study has shown that magnetic survey with application of different algorithms can present a clear picture of different changes in the direction of the magnetic field which suggests that the target location where the magnetic mineral is of more significance is within that region of the map. Based on the results obtained from the interpretation of aeromagnetic dataset in Akure, Southwestern Nigeria have shown materials with magnetic minerals like metamorphic and igneous rocks while in other areas revealed materials with non-magnetic minerals like faults, fractures, rock contacts and joints between two rocks along the grid lines been investigated in the area.

\section{REFERENCES}

[1] Reeves, C. 2006. Aeromagnetic surveys; principles, practice and Interpretation. Geosoft, 155.

[2] Grant, F.S. 1973. The magnetic susceptibility mapping method for interpreting aeromagnetic surveys. Presented at the 43rd Annual International Meeting of the Society of Exploration Geophysicists, Mexico City.

[3] Nabighian, M.N., Grauch, V.J.S., Hansen, R.O., LaFehr, T.R., Li, Y., Peirce, J.W., Phillips, J.D., Ruder, M.E. 2005. The historical development of the magnetic method in exploration. Geophysics, 70, 33-61.

[4] Li, X. 2003. On the use of different methods for estimating magnetic depth. The Leading Edge, 22(12), 1090-1099.

[5] Goussev, S.A., Charters, R.A., Peirce, J.W., Glenn, W.E. 2003. Jackpine Creek magnetic anomaly: Identification of a buried meteorite impact structure. The Leading Edge, 22, 740-741.

[6] Grauch, V.J.S., Hudson, M.R., Minor, S.A., Caine, J.S. 2006. Sources of a long-strike variation in magnetic anomalies related to intra-sedimentary faults: A case study from the Rio-Grande Rift.

[7] Okpoli, C.C., Akingboye, A.S. 2016. Reconstruction and appraisal of Akunu-Akoko iron ore deposits using geological and magnetic approaches. RMZ-M\&G, 63(1), 19-38.

[8] Okpoli, C.C., Eyitoyo, F.B. 2016. Aeromagnetic study of Okitipupa region, Southwestern Nigeria. International Basic and Applied Research Journal, 2(7), 1-20.

[9] Ademeso, O.A., Alabi, K. 2011. Geochemical Characteristics of the Charnockitic and Associated Granitic Rock, Akure Area, Southwestern Nigeria. Nature and Science, 9(5), 7-12.

[10] Rahaman, M.A. 1976. Review of the Basement Geology of Southwestern Nigeria. In: Kogbe, C.A. Geology of Nigeria. Elizabethan Pub. Co., Lagos, 41-58.

[11] Olujide, P.O., Udoh, A.N. 1989. Preliminary comments on the fracture systems of Nigeria. In: Proceedings of the national seminar on earthquakes in Nigeria, 97-109.

[12] Osinowo, O.0., Olayinka, A.I. 2013. Aeromagnetic Mapping of Basement Topography around the Ijebu-Ode Geological Transition Zone, Southwestern Nigeria. Acta Geodaetica et Geophysica, 48(3), 451-470.

[13] Adekoya, J.A., Kehinde, Philips, O.0., Odukoya, A.M. 2003. Geological distribution of mineral resources in Southwestern Nigeria. In: Elueze AA (Ed) project for investment in mineral resources of southwestern Nigeria, $1-13$

[14] Akingboye, A.S. 2014. Geology and Ground Magnetic Investigation over Iron ore deposit, Akunu-Akoko, Area Southwestern Nigeria. Adekunle Ajasin University. AKungba-Akoko; Unpublished, 115.

[15] Folami, S.L. 1992. Interpretation of Aeromagnetic Anomalies in Iwaraja Area, Southwestern Nigeria, Journal of Mining and Geology, 28(2), 391-396.

[16] Kayode, J.S., Nyabese, P., Adelusi, O.A. 2010. Ground magnetic study of Ilesha East, southwestern Nigeria. African Journal of Environmental Science and Technology, 4(3), 122-131.

[17] Okunlola, O.A., Ofonime, B.E. 2006. Geological setting, petrographical features and age of rare metal (Ta-Nb) mineralization of pegmatite of
Komu area, Southwestern Nigeria. African Journal of Science and Technology (AJST), Science and Engineering Series, 7(1), 96-110.

[18] Adagunodo, T.A., Sunmonu, L.A., Aanuoluwa, T., Olafisoye, E.R. Oladejo, O.P. 2012. Interpretation of Ground magnetic data in Oke-Ogba Area, Akure, Southwestern Nigeria. Advances in Applied Science Research, (5), 3216-3222

[19] Ademeso, 0.A. 2009. Deformation traits in the charnockitic rocks of Akure area, Southwestern Nigeria. Asian Journal of Earth Sciences, 2(4) 113-120.

[20] Ajayi, T.R., Ogedengbe, 0. 2003. Opportunity for the Exploitation of Precious and Rare Metals in Nigeria. In: Elueze AA (Ed.), Prospects for Investment in Mineral Resources of Southwestern Nigeria, 15-26.

[21] Rahaman, M.A. 1988. Recent advances in the study of the basement complex of Nigeria. In: Geological Survey of Nigeria (Ed) Precambrian Geol Nigeria, 11-43.

[22] Odeyemi, I. 1981. A Review of the Orogenic Events in the Precambrian Basement of Nigeria, West Africa. Geologische Rundschau, 70, 897-909.

[23] Anifowose, A.Y.B. 2004. Remote sensing analysis of Ifewara-Zungeru Megalinear in Nigeria (thesis). Akure: Federal University of Technology, 169

[24] Okonkwo, C.T. 1992. Structural geology of basement rocks of Jebba area, Nigeria. Journal of Mining and Geology, 35(1), 9-21.

[25] Foss, C. 2011. Magnetic data enhancement and depth estimation. In Gupta H ed. Encyclopedia of Earth Sciences Series, 736-746.

[26] Gunn, P., Maidment, D., Milligan, P. 1997. Interpreting aeromagnetic data in areas of limited outcrop. AGSO Journal of Australian Geology \& Geophysics, 17(2), 175-185.

[27] Telford, W.M., Geldart, L.P., Sheriff, R.E. 1990. Applied Geophysics 2nd Edition Cambridge University Press.

[28] Roest, W.R., Verhoef, J. 1992. Pilkington M: Magnetic interpretation using the 3-D analytic signal. Geophysics, 57, 116-125.

[29] Milligan, P., Gunn, P. 1997. Enhancement and presentation of airborne geophysical data. AGSO Journal of Australian Geology \& Geophysics, 17(2), $63-75$

[30] Werner, S. 1953. Interpretation of magnetic anomalies of sheet-like bodies. Sveriges Geologiska Arsbok, Stockholm, 43.

[31] Hartman, R.R., Teskey, D.J., Friedberg, J. 1971. A system for rapid digital aeromagnetic interpretation. Geophysics, 36, 891-918.

[32] Ku, C., Sharp, J. 1983. Werner deconvolution for automated magnetic interpretation and its refinement using Marquart's inverse modeling. Geophysics, 48(6), 754-774.

[33] Graham, K.M. 2013. Geological and structural interpretation of part of the Buem Formation, Ghana, using aerogeophysical data, 134.

[34] Phillips, J.D., Saltus, R.W., Reynolds, R.L. 1998. Sources of magnetic anomalies over a sedimentary basin - preliminary results from the Coasta Plain of the Arctic National Wildlife Refuge, Alaska. In: Gibson RI, Millegan PS, editors. Geologic Applications of Gravity and Magnetics: Case Histories: Society of Exploration Geophysicists and American Association of Petroleum Geologists, 130-134

[35] Barbosa, V.C.F., Silva, J.B.C., Medeiro, W.E. 1999. Stability analysis and improvement of structural index estimation in Euler deconvolution. Geophysics, 64, 48-60.

[36] Reid, A.B., Allsop, I.M., Grsner, H., Millet, A.J., Somerton, I.W. 1990. Magnetic interpretation in three dimensions using euler deconvolution. Geophysics, 55, 80-91.

[37]Fitzgerald, D., Reid, A., McInerney, P. 2003. New discrimination techniques for Euler deconvolution, 8th SAGA Biennial Technical Meeting and Exhibition.

[38] Hurley, P.M., Rand, J.R. 1969. Pre-drift continental nuclei. 
[39] Mushayandebvu, M.F., van Driel, P., Reid, A.B., Fairhead, J.D. 2001. Magnetic source parameters of two-dimensional structures using extended Euler deconvolution. Geophysics, 66, 814-823.

[40] Nabighian, M.N., Hansen, R.O. 2001. Unification of Euler and Werner deconvolution in three dimensions via the generalised Hilbert transform. Geophysics, 66, 1805-1810.

[41] Thompson, D.T. 1982. EULDPH-A New Technique for Making Computer Assisted Depth Estimates from Magnetic Data. Geophysics, 47, 31-37.

[42] Yaghoobian, A., Boustead, G.A., Dabush, T.M. 1992. Object delineating using Euler's homogeneity equation, Proceedings of SAGEEP, 92.

[43] Florio, G., Fedi, M., Pasteka, R. 2006. On the application of euler deconvolution to the analytical signal, Geophysics, 71, 87-93.

[44] El Dawi, M.G., Tianyou, L., Hui, S., Dapeng, L. 2004. Depth estimation of 2-D magnetic anomalous sources by using euler deconvolution method. American Journal of Applied Sciences, (1/3), 209-214.

[45] Briggs, I.C. 1974. Machine Contouring Using Minimum Curvature. Geophysics, 39, 39-48.

[46] Kivior, I., Boyd, D. 1998. Interpretation of the Aeromagnetic Experimental Survey in the Eromanga/Cooper Basin. Canadian Journal of Exploration Geophysics, 34/1-2, 58-66.

[47] Blanco-Montenegro, I., Torta, J.M., García, A., Araña, V. 2003. Analysis and modelling of the aeromagnetic anomalies of Gran Canaria (Canary Islands): Earth Planet. Science Letters, 206, 601-616.

[48] Adagunodo, T.A., Sunmonu, L.A., Aanuoluwa, T., Olafisoye, E.R., Oladejo, O.P. 2012. Interpretation of ground- magnetic data in Oke-Ogba Area, Akure, Southwestern Nigeria. Advances in Applied Science Research,

\section{3(5), 3216-3222.}

[49] Fasunwon, O.O., Olowofela, J.A., Akinyemi, O.D., Asunbo, A. 2007. Ground-magnetic study of Ijapo Area of Akure, Ondo State, Nigeria, 19(1), 89-96.

[50] Manhall, M., Cox, A. 1972. Magnetic changes in pillow basalt due to seafloor weathering. Journal of Geophysical Research, 77, 6459-6469.

[51] Bleil, U., Petersen, N. 1983. Variation in magnetization intensity and low-temperature titanomagnetite oxidation of ocean floor basalts. Nature. 301,384388

[52] Sunmonu, L.A., Alagbe, O.A. 2014. Interpretation of Aeromagnetic Data of Kam, Using Semi-Automated Techniques. International Research Journal of Earth Sciences, 2(2), 1-18.

[53] Amigun, J.O., Afolabi, O., Ako, B.D. 2012. Application of airborne magnetic data to mineral exploration in the Okene Iron Ore Province of Nigeria Prospect for Investment in Mineral Resources. International Research Journal of Geology and Mining, 2(6),132-140.

[54] Silva, A., Pires, A.A., Mccafferty, R., De Moraes, H., Xia. 2003. Application of airborne geophysical data to mineral exploration in the uneven exposed terrains of the Rio das Velhas Greenstone Belt. Revista Brasileira de Geociências, 33, 17-28.

[55] Alagbe, O.A. 2015. Depth estimation of Aeromagnetic Data of Kam. International Journal of Advanced Research in Physical Science, 2(1), 3752.

[56] Cooper, G.R.J., Cowan, D.R. 2004. Filtering using variable order vertical derivatives, Computers and Geosciences, 30, 455-459.

[57] Mushayandebvu, M., van Drielz, P., Reid, A., Fairhead, J. 2001. Magnetic source parameters of two-dimensional structures using extended euler deconvolution. Geophysics, 66(3), 814-823. 